\title{
Acute renal failure due to trichloroethylene poisoning
}

\author{
N J DAVID,' R WOLMAN,' F J MILNE,' I VAN NIEKERK ${ }^{2}$ \\ From the Department of Internal Medicine, ${ }^{\prime}$ Coronation Hospital and University of the Witwatersrand, and \\ Department of Anatomical Pathology, ${ }^{2}$ School of Pathology, South African Institute for Medical Research and \\ University of the Witwatersrand, Johannesburg, Republic of South Africa
}

In this unusual case of trichloroethylene (TCE) poisoning the patient developed acute renal failure with few of the other features of TCE toxicity. Nephrotoxicity is thought to be a rare complication of TCE toxicity and only one report of proved acute tubular necrosis is available. ${ }^{1}$

\section{Case report}

A 34 year old man with no previous medical illnesses worked in a factory manufacturing computer ribbons. In early February 1987 he was exposed for eight hours to 7.51 of a $99.5 \%$ pure solution of TCE while cleaning the ink off old ribbons for subsequent reuse. The room in which he was working measured $10 \times 20 \times 4 \mathrm{~m}$ with an open door at both ends. Most windows in the room were closed. The man was gloved but no mask was provided. His symptoms began the next day.

Initially, there was drowsiness and a distaste for alcohol and nicotine. He became short tempered and began vomiting after meals. One week after exposure he developed swelling of his feet and face, with bilateral loin tenderness, frequency of micturition, dysuria and urgency but with a decreased urine volume. He presented to hospital three weeks after exposure. Examination showed a well built man who was in no distress and appeared generally well. His blood pressure was $170 / 110 \mathrm{~mm} \mathrm{Hg}$ and there was bilateral renal angle and suprapubic tenderness. Pronounced pedal oedema was present. The chest $x$ ray film showed small bilateral pleural effusions but the lung fields were clear. The ECG was normal.

Urine analysis showed $2+$ proteinuria, 375000 red cells $/ \mathrm{mm}^{3}$ (of which $25 \%$ were dysmorphic), and 45000 white cells $/ \mathrm{mm}^{3}$. No casts or eosinophils were noted. The urine sodium concentration was $46 \mathrm{mmol} / 1$ and the urine osmolality $220 \mathrm{~m} 0 \mathrm{sm} / \mathrm{kg}$ on a spot specimen. Ultrasound examination of the abdomen showed normal sized kidneys with smooth outlines, a small amount of ascites, and bilateral pleural effusions. No renal calculi or hydronephrosis was

Accepted 23 May 1988 noted. The blood urea concentration was $40 \mathrm{mmol} / 1$ (range $=2 \cdot 5-6.6$ ) and the serum creatinine concentration was $1148 \mu \mathrm{mol} / \mathrm{l}(<130)$ but the serum electrolytes were normal. The serum urate concentration was raised to $0.96 \mathrm{mmol} / 1$ (range $=0.2-0.48$ ), the calcium was low $(2.0 \mathrm{mmol} / \mathrm{l}$; range $=2 \cdot 15-2.65)$, and the phosphorus was high $(2.26 \mathrm{mmol} / \mathrm{l}$; range $=0.81$ 1.45). The white cell count was $9.3 \times 10^{9} / 1$ with a normal eosinophil count. The antinuclear factor was negative as was the rheumatoid factor. Protein electrophoresis was normal with normal immunoglobulins but the IgE concentration was not measured. Serum complement concentrations (C3 and $\mathrm{C} 4)$ were also normal. The serum $\gamma$-glutamyl transpeptidase and alanine-amino transferase concentrations were raised but the other liver function tests gave normal results.

The day after admission he became polyuric with a urine output of 2.71 over 24 hours with a creatinine clearance of $7 \mathrm{ml} / \mathrm{min}$ and a protein excretion of $0.89 \mathrm{~g} /$ $24 \mathrm{~h}$. Dialysis was not indicated and the patient was treated on a low protein diet, furosemide $80 \mathrm{mg}$ and $\alpha$-methyldopa $500 \mathrm{mg}$ both 12 hourly.

Tru-cut needle biopsy of the kidney was performed three days after admission once the patient was normotensive. Two cores of renal cortical and medullary tissue were studied in which a total of seven glomeruli were present. All the glomeruli were within normal limits. The interstitium showed a patchy mononuclear cell infiltrate with large numbers of eosinophils. The infiltrate was related to tubules containing "hard" eosinophilic casts associated with damage to the tubular epithelial cells and rupture of the tubular basement membrane (figure). In addition, there was mild diffuse interstitial oedema but no interstitial fibrosis was present. The renal tubular lining cells showed evidence of florid regenerating acute tubular necrosis. The vessels appeared essentially normal. The glomerulus examined by electron microscopy showed patent capillary loops. The visceral epithelial cells showed small focal areas of foot process effacement. The basement membrane appeared slightly wrinkled. A mild increase in mesangial matrix was noted and a few isolated electron dense 


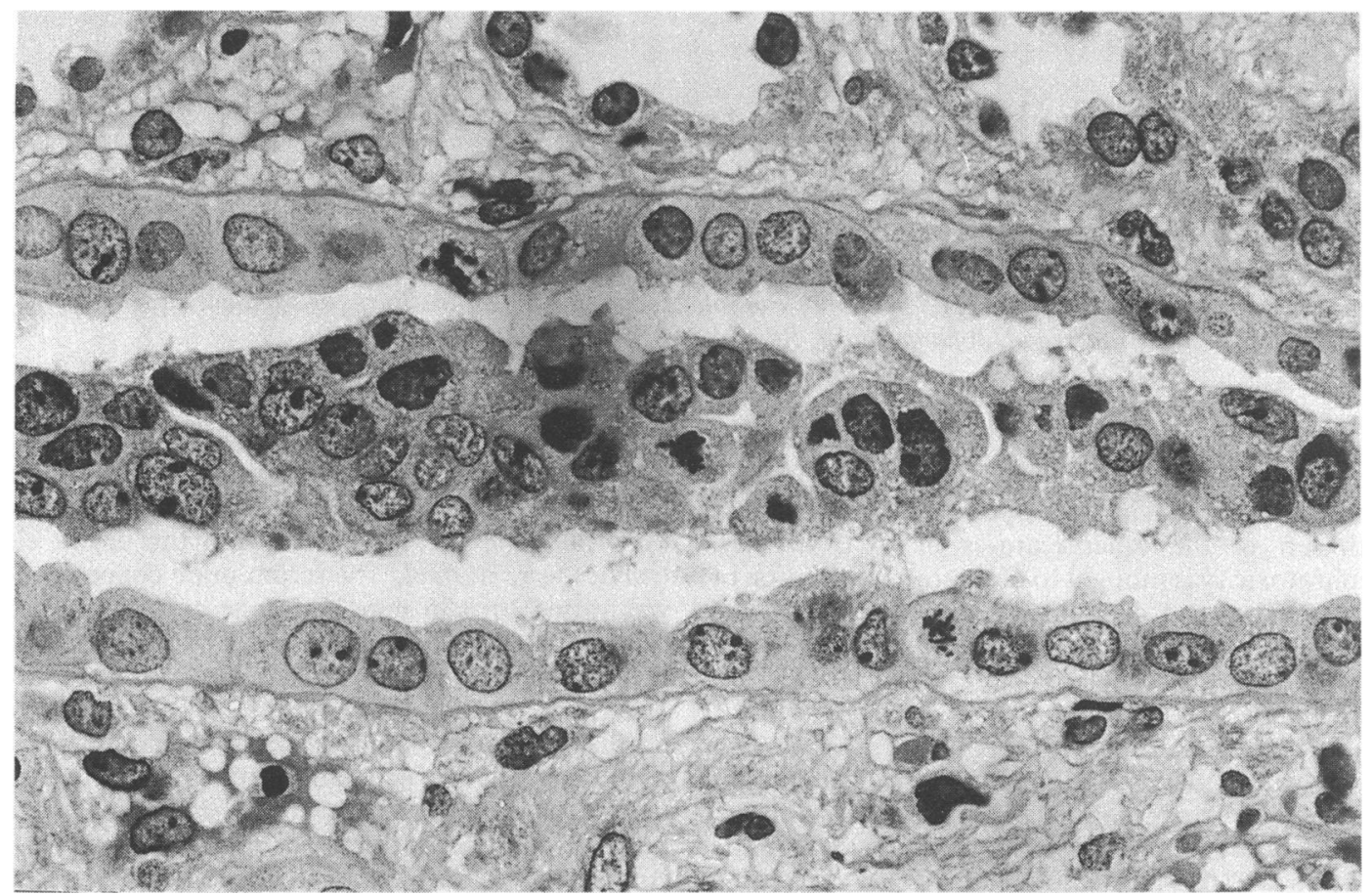

Renal tubule showing florid regenerating acute tubular necrosis-that is, mitotic activity of lining cells with an intraluminal eosinophilic cast. (Haematoxylin and eosin $\times 400$ ).

deposits were observed within the mesangial matrix. Immunofluorescence studies were negative apart from mild IgM deposition in the mesangium.

The patient made an uneventful recovery with steady improvement in his renal function. Eight months later there were no urinary abnormalities and his renal function was normal. Nevertheless, he was noted on two occasions to have mild hypertension.

\section{Discussion}

The main danger from acute exposure to TCE results from the agent's anaesthetic action leading to narcosis, central respiratory failure, and death. ${ }^{1}$ Nephrotoxicity after acute intoxication appears to be rare. One case of biopsy proved acute renal failure due to acute tubular necrosis in a metal degreaser using TCE has been documented.' Glomerulonephritis has been produced in experimental animals given oral doses of TCE over a prolonged period. ${ }^{2}$ The cause of the acute renal failure in our patient was predominantly on the basis of acute allergic interstitial nephritis with secondary tubular necrosis and tubular obstruction from intraluminal casts. We cannot account for the mesangial IgM deposition and the electron dense deposits on electron microscopy. The renal lesion seems to have resolved in our patient, but the mild hypertension may

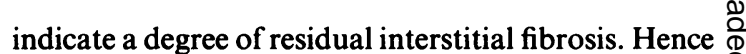
the prognosis of this form of TCE acute interstitial nephritis appears to be good without treatment with corticosteroids.

This patient was also unusual because of the absence of any other manifestations of TCE toxicity apart from the symptoms described immediately after exposure. Possibly the renal damage may have been 3 produced by contaminants in the solution. The $\frac{5}{3}$ patient's employer has informed us that the solution used was $99.5 \%$ pure, which is the same as that which 0 was used in the case previously recorded. ${ }^{1}$ No other nephrotoxic agents were used. Circumstantial 은 evidence is thus strongly in favour of renal damage $D$ subsequent to inhalation of a subnarcotic dose of TCE.

To protect workers against excessive exposure to $\%$ TCE vapour an industrial threshold limit value (TLV) $\stackrel{N}{\circ}$ of $100 \mathrm{ppm}$ has been established. The odour of TCE is $\omega$ first detectable at a level of $60 \mathrm{ppm},{ }^{3}$ although this threshold rapidly rises to about $166 \mathrm{ppm}$ with con- 0 tinued exposure. ${ }^{1}$ Our patient reported a strong odour $\stackrel{\bar{D}}{\mathcal{D}}$ over the entire eight hour period during which he was $\stackrel{?}{?}$ exposed to TCE. He probably inhaled a concentration 7 of above $166 \mathrm{ppm}$ but below the narcotic level of 3700 $\mathrm{ppm}$ and the anaesthetic level of $10000 \mathrm{ppm} .{ }^{45} \mathrm{He}$ had previously worked with TCE but not for so long as on 
this occasion. This previous exposure may have been important in the pathogenesis of his present renal disease.

We think that this patient's working conditions were not extraordinary and probably many workers are exposed to TCE vapour concentrations greater than the established TLV of $100 \mathrm{ppm}$. The scarcity of reports such as this would suggest that most cases of overexposure to TCE vapour are uncomplicated by organ damage or result in organ damage that is subclinical. In view of these reports, however, all who work with this common hydrocarbon solvent should ensure that vapour concentrations remain within the TLV and should be fully aware of the possible serious consequences of overexposure.

\section{References}

1 Gutch CF, Tomhave WG, Stevens SC. Acute renal failure due to inhalation of trichloroethylene. Ann Intern Med 1965;63: 128-34.

2 Lande P, Dervillee P, Nun C. Recherches experimentales sur l'action toxique du trichloréthylène. Archives des Maladies Professionnelles de Médecine du Travail et de Sécurite Sociale 1939;2:454-63.

3 Hargarten JJ, Hetrick GH, Fleming AJ. Industrial safety experience with trichloroethylene. Its uses as a vapour degreasing solvent 1948-1957. Arch Environ Health 1961;3:461-7.

4 Langley EO, Jones R. Acute trichloroethylene narcosis. Accident involving the use of trichloroethylene in a confined space. Arch Environ Health 1963;7:249-52.

5 Browning E. Toxicity and metabolism of industrial solvents. Amsterdam: Elsevier, 1965:189-212. 